\title{
Celecoxib reduces brain dopaminergic neuronaldysfunction, and improves sensorimotor behavioral performance in neonatal rats exposed to systemic lipopolysaccharide
}

Asuka Kaizaki ${ }^{1,3}$, Lu-Tai Tien², Yi Pang ${ }^{1}$, Zhengwei Cai ${ }^{1}$, Sachiko Tanaka ${ }^{3}$, Satoshi Numazawa ${ }^{3}$, Abhay J Bhatt $^{1}$ and Lir-Wan Fan ${ }^{1 *}$

\begin{abstract}
Background: Cyclooxygenase-2 (COX-2) is induced in inflammatory cells in response to cytokines and pro-inflammatory molecules, suggesting that COX-2 has a role in the inflammatory process. The objective of the current study was to examine whether celecoxib, a selective COX-2 inhibitor, could ameliorate lipopolysaccharide (LPS)-induced brain inflammation, dopaminergic neuronal dysfunction and sensorimotor behavioral impairments.

Methods: Intraperitoneal (i.p.) injection of LPS (2 mg/kg) was performed in rat pups on postnatal Day 5 (P5), and celecoxib $(20 \mathrm{mg} / \mathrm{kg}$ ) or vehicle was administered (i.p.) five minutes after LPS injection. Sensorimotor behavioral tests were carried out $24 \mathrm{~h}$ after LPS exposure, and brain injury was examined on P6.

Results: Our results showed that LPS exposure resulted in impairment in sensorimotor behavioral performance and injury to brain dopaminergic neurons, as indicated by loss of tyrosine hydroxylase (TH) immunoreactivity, as well as decreases in mitochondria activity in the rat brain. LPS exposure also led to increases in the expression of a-synuclein and dopamine transporter proteins and enhanced $\left[{ }^{3} \mathrm{H}\right]$ dopamine uptake. Treatment with celecoxib significantly reduced LPS-induced sensorimotor behavioral disturbances and dopaminergic neuronal dysfunction. Celecoxib administration significantly attenuated LPS-induced increases in the numbers of activated microglia and astrocytes and in the concentration of IL-1 $\beta$ in the neonatal rat brain. The protective effect of celecoxib was also associated with an attenuation of LPS-induced COX-2+ cells, which were double labeled with TH + (dopaminergic neuron) or glial fibrillary acidic protein (GFAP) + (astrocyte) cells.

Conclusion: Systemic LPS administration induced brain inflammatory responses in neonatal rats; these inflammatory responses included induction of COX-2 expression in TH neurons and astrocytes. Application of the COX-2 inhibitor celecoxib after LPS treatment attenuated the inflammatory response and improved LPS-induced impairment, both biochemically and behaviorally.
\end{abstract}

Keywords: Cyclooxygenase-2, Dopamine uptake, Substantia nigra, Microglia, Astrocyte

\footnotetext{
* Correspondence: LWFan@umc.edu

'Department of Pediatrics, Division of Newborn Medicine, University of

Mississippi Medical Center, Jackson, MS 39216, USA

Full list of author information is available at the end of the article
} 


\section{Background}

In humans, the timing of maternal infection during pregnancy appears to play a crucial role in the neurodevelopmental responses/outcomes of offspring, and late gestational infection has been reported to induce perseverative behavior, which is implicated in schizophrenia and autistic spectrum disorders [1]. Human fetal brain development at late gestation roughly corresponds to the early postnatal period in rats (postnatal Day 7 (P7) in rats equals roughly the time of birth in humans) [2]. Our recent studies have shown that neonatal exposure to lipopolysaccharide (LPS) through an intracerebral (i.c.) injection in the rat brain (at P5, relevant to human intrauterine infection in late gestation) can produce brain inflammation, nigrostriatal dopaminergic injury and neurobehavioral dysfunction [3-8]. LPS, a component of the cell wall in gram-negative bacteria, is responsible for most of the inflammatory effects of infection from gram-negative bacteria. LPS has been detected in the amniotic fluid [9]. Thus, it is possible that LPS may reach the fetal brain during maternal infection.

Microglia have been identified as the major LPSresponsive cells in the central nervous system (CNS) [10]. Activation of microglia plays a critical role in perinatal i.c. LPS-induced dopaminergic neuronal injury in the rat brain $[4,5,7,8]$. Interaction of microglial cells with apoptotic neurons has been reported to selectively promote cyclooxygenase-2 (COX-2) expression, and COX-2 may mediate microglial activation and may play a key role in amplifying the inflammatory response with toxic effects $[11,12]$. In the CNS, COX-2 may have a physiological role; however, COX-2 is induced in inflammatory cells in response to cytokines and pro-inflammatory molecules, suggesting that COX-2 has a role in the inflammatory processes $[11,13]$. COX-2 is primarily responsible for prostanoid production in acute and chronic inflammatory processes, and its inhibition leads to anti-inflammatory effects $[11,13]$. COX-2 has also been hypothesized to be involved in many neurodegenerative diseases, such as multiple sclerosis, amyotrophic lateral sclerosis, Parkinson's disease, Creutzfeldt-Jakob disease and Alzheimer's disease [13].

Celecoxib is a selective COX-2 inhibitor and the safest COX-2 inhibitor in terms of cardiovascular safety data [14]. The neuroprotective action of celecoxib has been observed in the LPS-induced nigrostriatal neurodegeneration [15] and 6-hydroxydopamine (6-OHDA)-induced progressive dopaminergic neuron degeneration in a rat model of Parkinson's disease [16]. The objective of the present study was to investigate whether systemic LPS exposure (at P5) through an i.p. injection also induced central inflammation, brain dopaminergic neuronal injury and sensorimotor behavioral deficits in our neonatal rat model whether celecoxib offered protection against LPS-induced brain inflammation and dopaminergic neuronal injury and improved sensorimotor behavioral performance in neonatal rats.

\section{Methods}

\section{Chemicals}

Unless otherwise stated, all chemicals used in this study were purchased from Sigma (St. Louis, MO, USA). Monoclonal mouse antibodies against $\beta$-amyloid precursor protein (APP), glial fibrillary acidic protein (GFAP), and $\alpha$-synuclein were purchased from Millipore (Billerica, MA, USA; APP and GFAP) and BD Bioscience (San Jose, CA, USA; $\alpha$-synuclein). Polyclonal rabbit antibodies against tyrosine hydroxylase (TH) and ionized calcium binding adapter molecule 1 (Iba1) were obtained from Millipore and Wako Chemicals USA (Irvine, CA, USA), respectively. Polyclonal rat antibodies against dopamine transporter (DAT) and polyclonal goat antibodies against COX-2 were obtained from Santa Cruz Biotechnology (Santa Cruz, CA, USA). $\left[{ }^{3} \mathrm{H}\right]$ Dopamine $\left(\left[{ }^{3} \mathrm{H}\right] \mathrm{DA}\right.$, specific activity $34.6 \mathrm{Ci} / \mathrm{mmol}$ ) was purchased from PerkinElmer (Boston, MA, USA). Enzyme-linked immunosorbent assay (ELISA) kits for immunoassay of rat interleukin-1 $\beta$ (IL-1 $\beta)$ and tumor necrosis factor- $\alpha$ (TNF $\alpha$ ) were purchased from R\&D Systems (Minneapolis, MN, USA).

\section{Animals}

Timed pregnant Sprague-Dawley rats arrived in the laboratory on Day 19 of gestation. Animals were maintained in a room with a 12-h light/dark cycle and at constant temperature $\left(22 \pm 2^{\circ} \mathrm{C}\right)$. The day of birth was defined as postnatal Day 0 (P0). After birth, the litter size was adjusted to 12 pups per litter to minimize the effects of litter size on body weight and brain size. All procedures for animal care were conducted in accordance with the National Institutes of Health Guide for the Care and Use of Laboratory Animals and were approved by the Institutional Animal Care and Use Committee at the University of Mississippi Medical Center. Every effort was made to minimize the number of animals used and their suffering.

\section{Animal treatment}

Injection of LPS $(2 \mathrm{mg} / \mathrm{kg}$ i.p., from Escherichia coli, serotype 055: B5) was performed in five-day-old SpragueDawley rat pups of both sexes. The control rats were injected with the same volume of sterile saline $(0.1 \mathrm{~mL})$. All animals survived the injection. Both LPS- and salineinjected animals were further divided into two groups: one received an i.p. injection of celecoxib (20 mg/kg), and the other group received an i.p. injection of vehicle. Celecoxib $(20 \mathrm{mg} / \mathrm{kg})$ was dissolved in $20 \%$ dimethyl sulfoxide (DMSO) in normal saline $[17,18]$ and administered immediately after the LPS injection. Thirty rats (15 male and 15 female pups) from each group were used in the 
present study. Behavioral tests were conducted in 12 rats from each group from P5 to P6. Rats were sacrificed on P6. Twenty-four rats from each group were sacrificed by decapitation to collect fresh brain tissue for Western blot analysis (six rats for each group), determination of the mitochondrial complex I activity (six rats for each group), ELISA assay (six rats for each group), and $\left[{ }^{3} \mathrm{H}\right] \mathrm{DA}$ uptake study (six rats for each group). Six additional rats from each group were sacrificed by transcardiac perfusion with normal saline followed by $4 \%$ paraformaldehyde for brain section preparation. Free-floating coronal brain sections of $40-\mu \mathrm{m}$ thickness were prepared in a freezing microtome (Leica, SM 2000R, Wetzlar, Germany) for immunohistochemistry staining.

\section{Behavioral testing}

Behavioral tests were performed as described by Fan et al. [4], with modifications. The developmental test battery that was used was based on previously documented tests for neurobehavioral toxicity $[19,20]$. Behavioral tests, including the righting reflex and negative geotaxis test, were performed for all rat pups from P5 to P6.

\section{Righting reflex}

This test is believed to be a reflection of muscle strength and subcortical maturation $[20,21]$. Pups were placed on their backs, and the time required to turn over on all four feet and touch the platform was measured. The cut-off time was $60 \mathrm{~s}$.

\section{Negative geotaxis}

This test is believed to test reflex development, motor skills, vestibular labyrinth and cerebellar integration $[19,20]$. Rats were placed on a $15^{\circ}$ incline with their heads pointing down the slope and had to turn to face upward and begin to crawl up the slope. Each pup was given three trials a day, and the time spent to make a turn of $180^{\circ}$ upward was recorded. The cut-off time was $60 \mathrm{~s}$.

\section{Immunohistochemistry}

Brain injury was estimated based on the results of immunohistochemistry in consecutive brain sections prepared from rats sacrificed one day (P6) after LPS injection. For immunohistochemistry staining, primary antibodies were used in the following dilutions: TH and Iba1, 1:500; GFAP, 1:200; and APP and COX-2, 1:100. TH was used to detect dopaminergic neurons in the substantia nigra $(\mathrm{SN})$. The amount of APP, a membrane-spanning glycoprotein, in normal axons and neurons is not enough to be detected, but the accumulation of APP can be detected as an early sign of axonal and neuronal lesions [22,23]. Microglia were detected using Iba1 immunostaining, which recognizes both resting and activated microglia. GFAP was used to detect astrocytes. COX-2 provided selective staining of inducible cyclooxygenase. Sections were incubated with primary antibodies at $4{ }^{\circ} \mathrm{C}$ overnight and further incubated with fluorescence-conjugated secondary antibodies (Alexa Fluor 555, 1:500 or Alexa Fluor 488, 1:200; Jackson Immunoresearch, West Grove, PA, USA) for $1 \mathrm{~h}$ in the dark at room temperature. DAPI (4',6-diamidino2-phenylindole) (100 ng/mL) was used simultaneously to identify nuclei in the final visualization. Sections incubated in the absence of primary antibodies were used as negative controls. When double-labeling was required, primary antibodies from different hosts were used in combination with appropriate secondary antibodies, which were raised against the immunoglobulin from the corresponding host. The resulting sections were examined under a fluorescent microscope (BX60, Olympus America Inc., Center Valley, PA, USA) at appropriate wavelengths.

\section{Immunoblotting analysis}

Protein expression of DAT and $\alpha$-synuclein was determined in P6 rat brains by Western blotting according to the methods of Fan et al. [7,8] and Hadlock et al. [24], with modifications. One day after LPS injection (P6), brains were quickly removed, and tissues were frozen in liquid nitrogen and stored at $-80^{\circ} \mathrm{C}$. Tissues were homogenized in an extraction buffer (Biosource, Camarillo, CA, USA), and a mixture of protease inhibitors (Calbiochem, La Jolla, CA, USA) and $1 \mathrm{mM}$ phenylmethylsulfonyl fluoride (PMSF) was added, accompanied by application of a Sonic Dismembrator (Fisher Scientific, Suwanee, GA, USA) three times for $10 \mathrm{~s}$ each. Protein levels of homogenates were determined by the Bradford method. The homogenates were diluted 1:2 (v/v) with Laemmli sample buffer. Equal quantities of protein $(10 \mu \mathrm{g} / 10 \mu \mathrm{L})$ were loaded into each well of a $4 \%$ to $20 \%$ SDS-polyacrylamide gradient gel (MINI-PROTEAN TGX, 4 to 20\%, Bio-Rad Laboratories, Hercules, CA, USA). The separated proteins were transferred electrophoretically to polyvinylidene difluoride (PVDF) membranes (Bio-Rad Laboratories) at $100 \mathrm{~V}$ for $1 \mathrm{~h}$. The blots were incubated with a blocking solution containing 5\% nonfat milk and $0.1 \%$ Tween-20 in Tris-buffered saline (TBS) for $1 \mathrm{~h}$ before incubation with the primary antibody $(1: 1,000)$ in the blocking solution overnight at $4^{\circ} \mathrm{C}$. The blots were then incubated with peroxidase-conjugated antibodies in blocking solution $(1: 4,000)$ for $1 \mathrm{~h}$ at room temperature. Immunoreactivity was detected by the Enhanced Chemiluminescence Plus or Advanced ECL system (GE Healthcare, Piscataway, NJ, USA). Images were acquired with the Chemidoc MP Imaging System followed by quantification using Image Lab software (both from Bio-Rad Laboratories). To ensure that equal amounts of protein were applied to the immunoblot, the membranes were stripped with a stripping buffer (Thermo Scientific, Rockford, IL, USA) and re-probed for $\beta$-actin (1:4,000, Sigma) to normalize the results. 


\section{Synaptosomal [3 H]DA (dopamine) uptake}

Uptake of $\left[{ }^{3} \mathrm{H}\right] \mathrm{DA}$ was determined according to the methods of Hadlock et al. [24] and Nickell et al. [25], with modifications. One day after LPS injection (P6), brain tissues were homogenized in ice-cold $0.32 \mathrm{M}$ sucrose $(50 \mathrm{mM}$ Tris buffer, $\mathrm{pH} 7.4)$ and centrifuged $(800 \times g$ for 12 minutes; $\left.4^{\circ} \mathrm{C}\right)$. The supernatant $(\mathrm{S} 1)$ was then centrifuged $\left(20,000 \times g\right.$ for 15 minutes; $\left.4^{\circ} \mathrm{C}\right)$, and the resulting pellets ( $\mathrm{P} 2$, synaptosomes) were resuspended in ice-cold water at concentrations of $2 \mathrm{mg} / \mathrm{mL}$ to lyse the synaptosomal membranes. Synaptosomal fractions were chilled at $4^{\circ} \mathrm{C}$ until DA uptake experiments commenced. Assays were performed in duplicate with a final volume of $250 \mu \mathrm{L}$. Aliquots of $25 \mu \mathrm{L}$ synaptosomal fractions ( $50 \mu \mathrm{g}$ of P2 protein) were added to tubes containing assay buffer $(126 \mathrm{mM} \mathrm{NaCl}, 4.8 \mathrm{mM} \mathrm{KCl}, 1.3 \mathrm{mM} \mathrm{CaCl}, 16 \mathrm{mM}$ $\mathrm{NaH}_{2} \mathrm{PO}_{4}, 1.4 \mathrm{mM} \mathrm{MgSO}, 11 \mathrm{mM}$ glucose and $1 \mathrm{mM}$ ascorbic acid, $\mathrm{pH}$ 7.4) and $1 \mu \mathrm{M}$ pargyline and then incubated at $37^{\circ} \mathrm{C}$ for five minutes. Nonspecific uptake was determined in the presence of $10 \mu \mathrm{M}$ nomifensine. Samples were placed on ice, and $25 \mu \mathrm{L}$ of $0.1 \mu \mathrm{M}\left[{ }^{3} \mathrm{H}\right] \mathrm{DA}$ (10 $\mathrm{nM}$ final concentration) was added to each tube, after which accumulation was permitted to proceed for five minutes at $37^{\circ} \mathrm{C}$. DA concentration and time of uptake were chosen based on the reports by Hadlock et al. [24] and Nickell et al. [25]. The reaction was terminated by the addition of $250 \mu \mathrm{L}$ ice-cold assay buffer and subsequent filtration, followed immediately by the washing two times of ice-cold assay buffer. Radioactivity retained by the filters was counted using a liquid scintillation counter (PerkinElmer). Nonspecific uptake, defined as DA uptake in the presence of $10 \mu \mathrm{M}$ nomifensine, was subtracted from total uptake to define DAT-mediated specific uptake.

\section{Determination of mitochondrial complex I activity}

Complex I activity was determined by a spectrophotometric assay based on the quantification of the rate of oxidation of the complex I substrate NADH to ubiquinone as described by Champy et al. [26] and Hoglinger et al. [27], with minor modifications. Brain tissues from each pup were collected at 6 or $24 \mathrm{~h}$ after LPS injection. The frozen brain tissue was homogenized mechanically, sonicated on ice in $10 \mathrm{mM}$ Tris- $\mathrm{HCl}$ buffer (pH 7.2) containing 225 $\mathrm{mM}$ mannitol, $75 \mathrm{mM}$ saccharose and $0.1 \mathrm{mM}$ EDTA, and then centrifuged $(600 \times g)$ for 20 minutes at $4^{\circ} \mathrm{C}$, to obtain post-nuclear supernatants. The optical density of the supernatants ( $40 \mu \mathrm{g}$ sample protein) in $1 \mathrm{~mL}$ an assay mixture was spectrophotometrically recorded at a wavelength of $340 \mathrm{~nm}$ for $200 \mathrm{~s}$ at $37^{\circ} \mathrm{C}$. The assay mixture was a potassium phosphate buffer $(25 \mathrm{mM}, \mathrm{pH} 7.5)$ containing $2 \mathrm{mM}$ potassium cyanide, $5 \mathrm{mM}$ magnesium chloride, $2.5 \mathrm{mg} / \mathrm{mL}$ bovine serum albumin, $2 \mu \mathrm{M}$ antimycin $\mathrm{A}$, $100 \mu \mathrm{M}$ decylubiquinone and $300 \mu \mathrm{M} \mathrm{NADH}$. The proportion of NADH oxidation sensitive to an excess of rotenone $(10 \mu \mathrm{M})$ was attributed to the activity of complex I. This procedure minimizes the dissociation of rotenone from complex I because of the use of small buffer volumes, maintenance at low temperatures, and rapid analysis. The specific activity (nmol NADH oxidation/ $\mathrm{min} / \mathrm{mg}$ protein) of complex I (NADH-ubiquinone oxidoreductase) was calculated using a molar extinction coefficient $\varepsilon_{340 \mathrm{~nm}}=6.22 \mathrm{mM}^{-1} \mathrm{~cm}^{-1}$ [28]. Enzyme activities were expressed as $\mathrm{nmol} / \mathrm{min} / \mathrm{mg}$ of brain tissue. Complex I activity was calculated as follows: Complex I activity $=$ (Rate $\left.\left(\mathrm{min}^{-1}\right) / \varepsilon_{340 \mathrm{~nm}}\left(6.22 \mathrm{mM}^{-1} \mathrm{~cm}^{-1}\right)\right) / 0.040 \mathrm{mg}$.

\section{Determination of IL-1 $\beta$ and TNFa protein by ELISA}

Two major pro-inflammatory cytokines, IL-1 $\beta$ and TNF $\alpha$, were determined by ELISA as previously described $[6,29]$. Briefly, brain tissues from each pup were collected $24 \mathrm{~h}$ after LPS injection, when the LPS-stimulated increase in inflammatory cytokines in the rat brain reached a peak value [30]. Brain tissues were homogenized by sonication in 1 $\mathrm{mL}$ ice-cold PBS (pH 7.2) and centrifuged at 12,000 $\times g$ for 20 minutes at $4{ }^{\circ} \mathrm{C}$. The supernatant was collected, and the protein concentration was determined by the Bradford method. ELISA was performed following the manufacturer's instructions, and data were acquired using a 96-well plate reader (Bio-Tek Instruments, Inc., Winooski, VT, USA). The cytokine contents were expressed as pg cytokine/mg protein.

\section{Quantification of data and statistics}

Brain sections at the bregma level and the midbrain sections at a level one-third rostral from the lambda to the bregma were used for determination of the most pathological changes. Most immunostaining data were quantified by the counting of positively stained cells. When the cellular boundary was not clearly separated, numbers of DAPI-stained nuclei from the superimposed images were counted as the cell number. Three digital microscopic images were randomly captured in each of the three sections, and the number of positively stained cells in the three images was counted and averaged $\left(\right.$ cells $\left./ \mathrm{mm}^{2}\right)$. The mean value of cell counts from three brain sections was used to represent one single brain. For convenience of comparison among the treatment groups, results were standardized as the average number of cells $/ \mathrm{mm}^{2}$. APP or COX-2 staining was quantified using National Institutes of Health (NIH) image software to determine the percentage area containing APP- or COX-2-positive staining in the entire area of the captured image [31]. In response to LPS challenge, the number of Iba1+ microglia and GFAP + astrocytes increases, and the soma of these cells become larger. In addition to cell density, Iba1 or GFAP immunoreactivity was also quantified by calculating 
the percentage area of the whole image containing Iba1 or GFAP immunostaining [7,8].

The behavioral data were presented as the mean \pm SEM and analyzed by one-way ANOVA followed by the Student-Newman-Keuls test. Data from immunostaining, immunoblotting analysis, $\left[{ }^{3} \mathrm{H}\right] \mathrm{DA}$ uptake, mitochondrial complex I activity and ELISA assay were presented as the mean \pm SEM and analyzed by one-way ANOVA followed by the Student-Newman-Keuls test. Results with a $P$-value of less than 0.05 were considered statistically significant.

\section{Results}

Celecoxib improved sensorimotor behavioral deficits induced by LPS exposure

Compared with the control group, LPS-injection in P5 rats resulted in sensorimotor behavioral deficits at P6 (Figure 1A, B). Celecoxib treatment significantly improved sensorimotor behavioral performance following LPS exposure (Figure 1A, B).

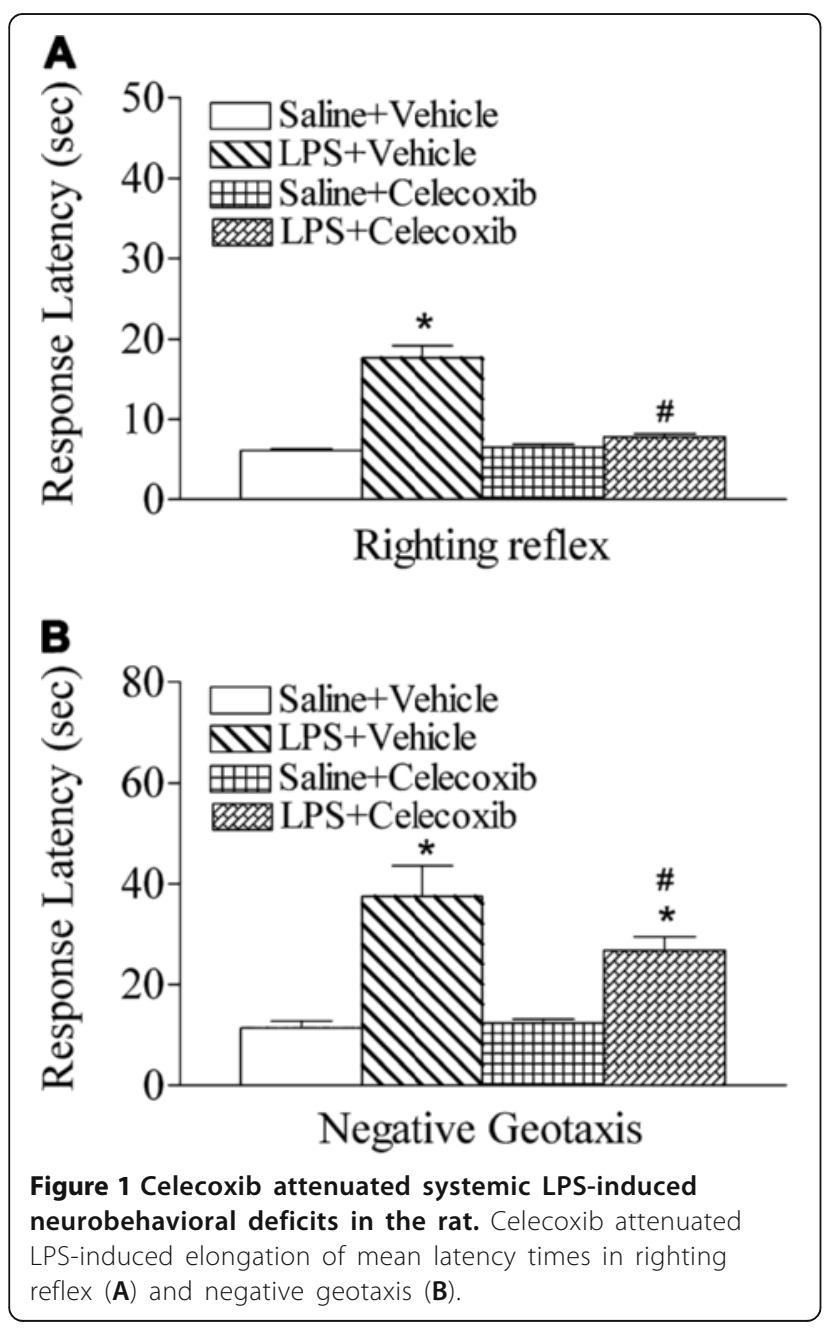

\section{Righting reflex}

The LPS-injected group exhibited significantly longer mean latency times as compared to the control group at P6 $(P<0.05$; Figure $1 \mathrm{~A})$. Celecoxib treatment significantly shortened the LPS-induced increase in righting reflex latency $(P<0.05)$, and there was no difference in righting reflex between the control and the LPS + celecoxib groups (Figure 1A).

\section{Negative geotaxis}

As shown in Figure 1B, the LPS-injected group exhibited significantly longer mean latency times for negative geotaxis along a $15^{\circ}$ incline as compared to the control group at P6 $(P<0.05)$. Celecoxib treatment significantly shortened the duration of the LPS-induced increase in negative geotaxis latency $(P<0.05$; Figure $1 \mathrm{~B})$.

\section{Celecoxib decreased LPS-induced dopaminergic neuronal and axonal damage}

Positive staining for $\mathrm{TH}$ was used to detect dopaminergic neurons in the SN. In the P6 control rat brain, TH-positive cells were more predominant in the compact and lateral regions of the SN (Figure 2A, G). As shown in Figure 2B, neonatal systemic LPS exposure suppressed TH expression in the $\mathrm{SN}$, as indicated by the reduced number of $\mathrm{TH}+$ neurons in the P6 rat brain $(P<0.05$; Figure $2 \mathrm{~B}, \mathrm{G})$. This result was similar to the reduction of $\mathrm{TH}+$ staining induced by i.c. LPS injection that we reported previously [5]. Celecoxib treatment attenuated the LPS-induced reduction in the number of TH-positive neurons $(P<0.05$; Figure $2 \mathrm{C}, \mathrm{G})$.

Up-regulation of APP, an early sign of axonal and neuronal lesions [22,23], was determined by immunostaining in the striatum of P6 rats. As shown in Figure 2D, weak expression of APP was barely detectable in the control rat brain. Beaded APP immunostaining was observed in the LPS-exposed brain $(P<0.05$; Figure $2 \mathrm{E}, \mathrm{H})$. Celecoxib treatment attenuated the LPS-induced injury to axons in the striatum, as indicated by weak APP immunostaining, which was similar to that observed in control rats $(P<0.05$; Figure 2F, $\mathrm{H})$.

\section{Celecoxib attenuated LPS-induced neuronal dysfunction} and decreases in mitochondrial complex I activity

Neonatal systemic LPS exposure not only increased the amount of DAT and $\alpha$-synuclein protein $(P<0.05$; Figure $3 \mathrm{Aa}, \mathrm{b})$, but also increased $\left[{ }^{3} \mathrm{H}\right] \mathrm{DA}$ uptake $(P<0.05$; Figure 3B). Dopamine uptake was measured by total $\left[{ }^{3} \mathrm{H}\right] \mathrm{DA}$ uptake into brain synaptosomes, as describe in the Methods section. These results revealed that LPS exposure may affect DAT function. Treatment with celecoxib significantly attenuated LPS-induced increases in the expression of $\alpha$-synuclein and DAT proteins, as well as $\left[{ }^{3} \mathrm{H}\right] \mathrm{DA}$ uptake $(P<0.05$; Figure $3 \mathrm{~A}, \mathrm{~B})$. 


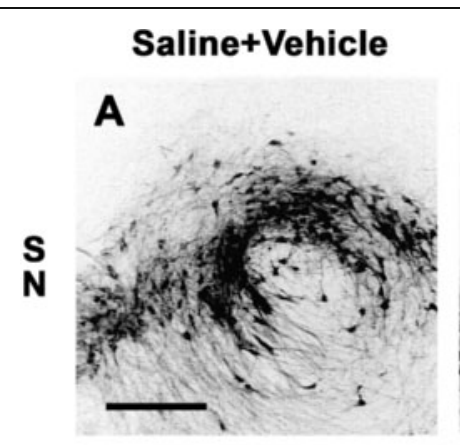

\section{LPS+Celecoxib}

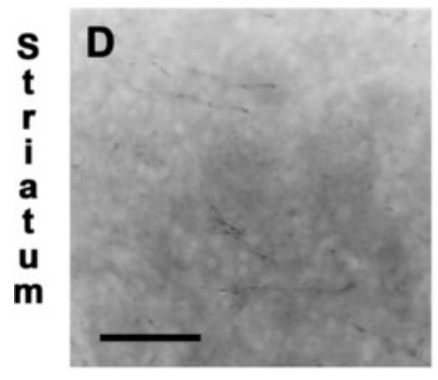

G

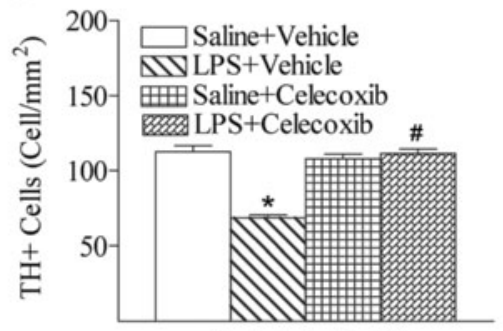

Substaintia Nigra
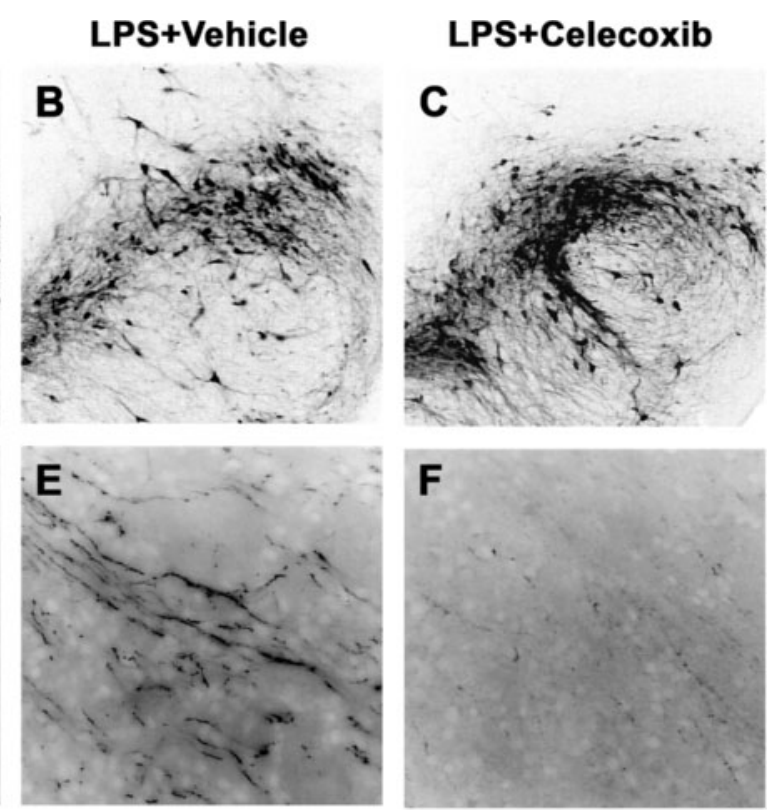

H

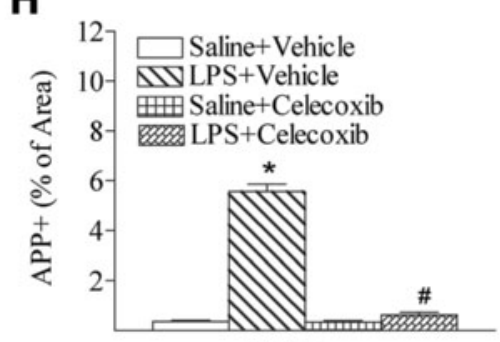

Striatum

Figure 2 Representative photomicrographs of TH (A to C, SN) and APP (D to F, striatum) immunostaining in the rat brain after LPS injection. TH positive staining was detected in the SN area (A) of the midbrain sections at a level one-third rostral from the lambda to the bregma in the control rat brain. LPS injection caused a loss of TH positive staining (B). Celecoxib attenuated the LPS-induced loss of TH positive staining (C). Weak APP positive staining was detectable in the brain sections at the bregma level of the control brain (D). The beaded APP staining was found in the striatum (E) of the LPS-exposed brain. Celecoxib treatment attenuated the LPS-induced injury to axons in the striatum (F). The scale bar shown in $\mathbf{A}$ represents $200 \mu \mathrm{m}$ for $\mathbf{A}$ to $\mathbf{C}$, or shown in $\mathbf{D}$ represents $50 \mu \mathrm{m}$ for $\mathbf{D}$ to $\mathbf{F}$. Quantitation of the number of TH positive cells in the SN $(\mathbf{G})$, and the percentage area of image that contained APP + staining in the cingulum white matter and the striatum were performed as described in Methods. The results are expressed as the mean \pm SEM of six animals in each group, and analyzed by one-way ANOVA. ${ }^{*} P<0.05$ represents a significant difference for the LPS + Vehicle group or LPS + Celecoxib group as compared with the Saline + Vehicle group. ${ }^{~} P<0.05$ represents a significant difference for the LPS + Celecoxib group as compared with the LPS + Vehicle group.

Mitochondrial complex I activity was measured as the amount of NADH oxidized per minute per milligram of protein in homogenates of whole brains of rats at $24 \mathrm{~h}$ after LPS injection. Systemic LPS exposure reduced enzymatic activity of mitochondrial complex I in $24 \mathrm{~h}$ (P6; $P<0.05$; Figure $3 \mathrm{C}$ ). Celecoxib treatment attenuated the LPS-induced decrease in mitochondrial complex I activity in $\mathrm{P} 6$ rat brains $(P<0.05$; Figure $3 C)$.

\section{Celecoxib decreased the LPS-induced increase in microglial activation and inflammatory responses}

Activated microglia were assessed by Iba1 immunostaining in the rat $\mathrm{SN}$ (Figure $4 \mathrm{~A}-\mathrm{C}, \mathrm{G}, \mathrm{H}$ ) and striatum (Figure 4D-H). LPS treatment triggered the activation of microglia in the SN (Figure 4B, G, H) and striatum (Figure 4E, G, H). In control rat brains, a few Iba1positive cells were detected, and most of these cells were in a resting state with a ramified shape in both the $\mathrm{SN}$ and striatum (arrows indicated in Figure 4A, D). Significantly increased numbers of activated microglia (Figure 4G) showing bright staining of an elongated or a round-shaped cell body with blunt or no processes were found in the $\mathrm{SN}$ and striatum (arrows indicated in Figure 4B, E) $24 \mathrm{~h}$ after LPS injection $(P<0.05)$. Iba1 staining was also quantified by measuring the percentage area containing Iba1 immunostaining in the captured images. Higher percentages of Iba1 immunostaining areas were observed in the $\mathrm{SN}$ and striatum of neonatal 


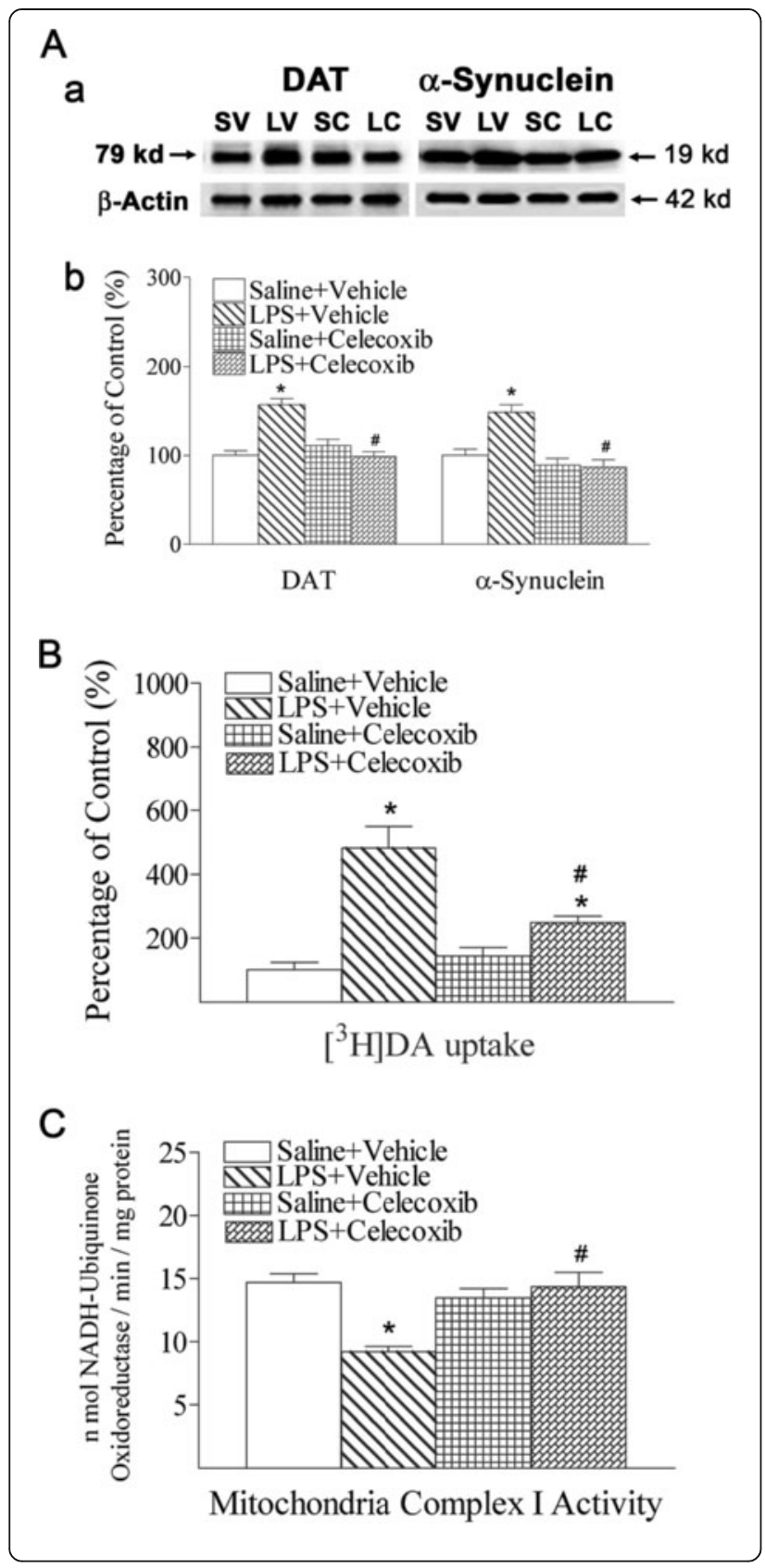

Figure 3 Celecoxib attenuated the systemic LPS-induced change in expression of DAT and a-synuclein (A), $\left[{ }^{3} \mathrm{H}\right] \mathrm{DA}$ uptake (B), and mitochondrial complex I enzymatic activity (C) in the rat brain. Aa, Western blotting of protein expression of DAT and a-synuclein in P6 rat brain. Ab, Expression of DAT (left panel of $\mathrm{Ab}$ ) and $\mathrm{a}$-synuclein (right panel of $\mathrm{Ab}$ ) is presented as the percentage of expression in the control group (Saline + Vehicle). Systemic LPS exposure increased DAT and a-synuclein expression in P6 rat brain. Celecoxib treatment attenuated the LPS-induced increase in expression of DAT and a-synuclein in the P6 rats. B, Dopamine uptake was measured by total $\left[^{3} \mathrm{H}\right] \mathrm{DA}$ uptake into brain synaptosomes and $\left[{ }^{3} \mathrm{H}\right] \mathrm{DA}$ uptake is presented as the percentage of data in the control group (Saline + Vehicle). LPS exposure increased $\left[{ }^{3} \mathrm{H}\right] \mathrm{DA}$ uptake in P6 rat brain. Celecoxib attenuated the LPS-induced increase in total $\left[^{3} \mathrm{H}\right] \mathrm{DA}$ uptake in the P6 rats. C, LPS exposure reduced enzymatic activity of mitochondrial complex I in 24 hours after LPS injection. Celecoxib treatment attenuated the LPS-induced decrease in mitochondrial complex I activity in P6 rats. The results are expressed as the mean \pm SEM of six animals in each group, and analyzed by one-way ANOVA. ${ }^{*} P<0.05$ represents a significant difference for the LPS + Vehicle group or LPS + Celecoxib group as compared with the Saline + Vehicle group. ${ }^{\#} P<0.05$ represents a significant difference for the LPS + Celecoxib group as compared with the LPS + Vehicle group.

LPS-exposed rat brains (Figure 4H). Celecoxib treatment reduced the number of activated microglia and percentage of Iba1 immunostaining area following LPS injection $(P<0.05$; Figure $4 \mathrm{C}, \mathrm{F}-\mathrm{H})$.

Systemic exposure to LPS resulted in inflammatory responses in the rat brain, as evidenced by the elevated expression of a major pro-inflammatory cytokine, IL-1 $\beta$ (Figure 5A). However, the concentration of TNF $\alpha$ in the rat brain returned to the control level $24 \mathrm{~h}$ after LPS exposure (Figure $5 \mathrm{~B}$ ). Treatment with celecoxib attenuated the induction of IL-1 $\beta$ content by LPS $(P<0.05$; Figure 5A).

\section{Celecoxib decreased the LPS-induced increase in astrocyte activation and COX-2 expression}

Development of hypertrophic morphology and upregulation of intermediate filament proteins, such as GFAP, by reactive astrocytes are perhaps the best known hallmarks of reactive astrocytes and reactive gliosis $[32,33]$. Increased expression of GFAP, an indication of astrogliosis, was observed at the SN (Figure 6B) and striatum (Figure 6E) $24 \mathrm{~h}$ after injection in rats exposed to systemic LPS (Figure 6G). In control rat brains, some GFAP-positive cells were detected, and most of these cells were in the resting state, with fine processes extending from the main cellular processes (arrows indicated in Figure 6A, D). Significantly increased numbers of reactive astrocytes showing hypertrophy of cellular processes of astrocytes (GFAP + cells) were found in the $\mathrm{SN}$ (arrows indicated in Figure 6B) and striatum (arrows indicated in Figure 6E) of rat brains $24 \mathrm{~h}$ after LPS injection $(P<0.05$; Figure $6 \mathrm{G})$. GFAP staining was also 


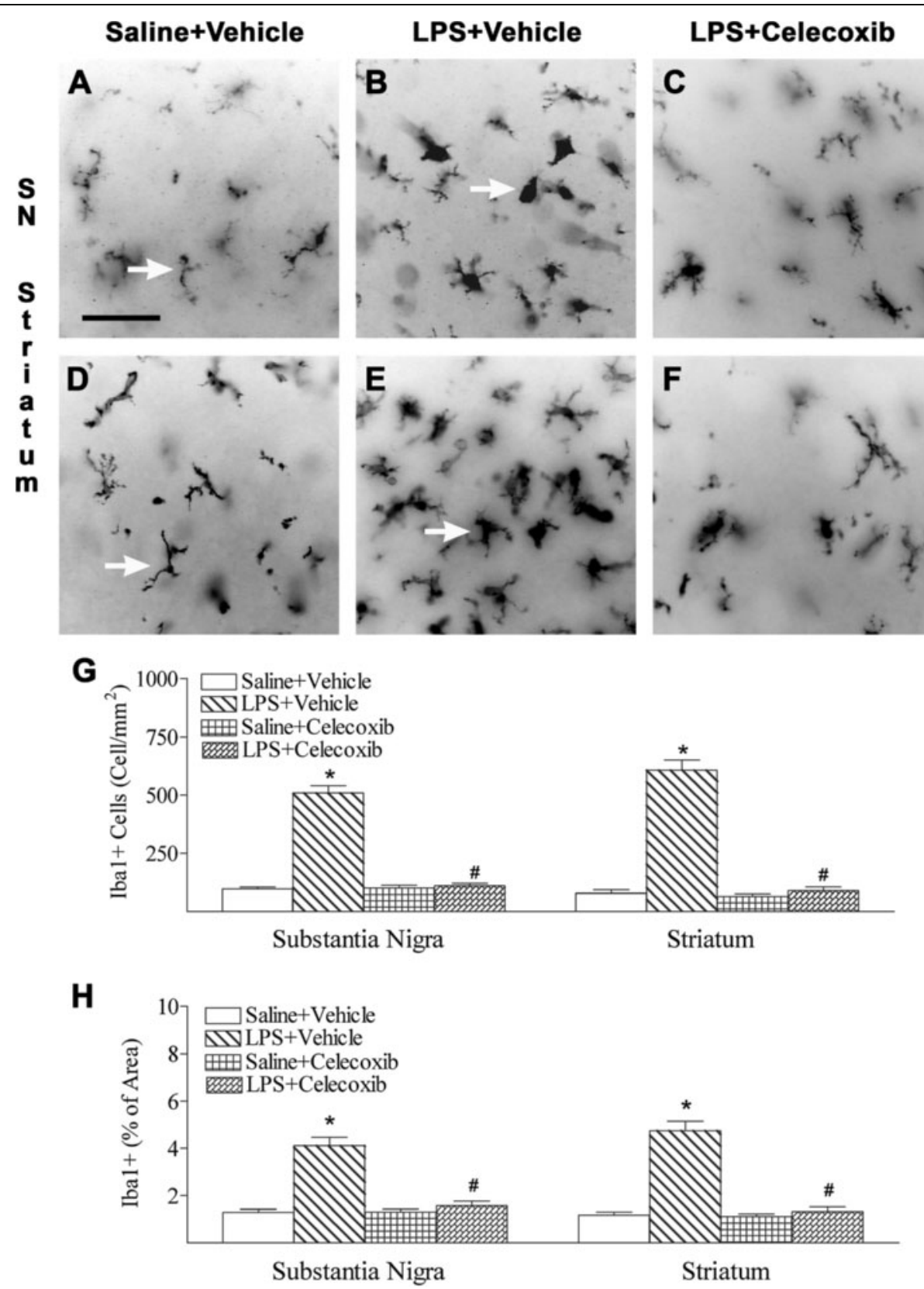

Figure 4 Representative photomicrographs of microglia (A to C, SN; D to F, striatum) in the rat brain after LPS injection. As shown by Iba1 immunostaining in the SN (A) and striatum (D), a few microglia at the resting status with a small rod-shaped soma and ramified processes (arrows indicated in $\mathbf{A}$ and $\mathbf{D}$ ) were found in the control rat brain. Numerous activated microglia showing bright staining of an elongated or a round shaped cell body with blunt or no processes (arrows indicated in $\mathbf{B}$ and $\mathbf{E}$ ) were observed in the SN (B) and striatum (E) of the rat brain with neonatal LPS exposure. Celecoxib treatment reduced the number of activated microglia stimulated by LPS in the above areas (C, $\mathbf{F}$ and $\mathbf{G})$. The scale bar shown in A represents $50 \mu \mathrm{m}$ for $\mathbf{A}$ to $\mathbf{F}$. Quantitation of the number of Iba1+ cells $(\mathbf{G})$ and the percentage area of image that contained Iba1 staining $(H)$ in the SN and striatum were performed as described in Methods. The results are expressed as the mean \pm SEM of six animals in each group, and analyzed by one-way ANOVA. ${ }^{*} P<0.05$ represents a significant difference for the LPS + Vehicle group as compared with the Saline + Vehicle group. ${ }^{\#} P<0.05$ represents a significant difference for the LPS + Celecoxib group as compared with the LPS + Vehicle group. 


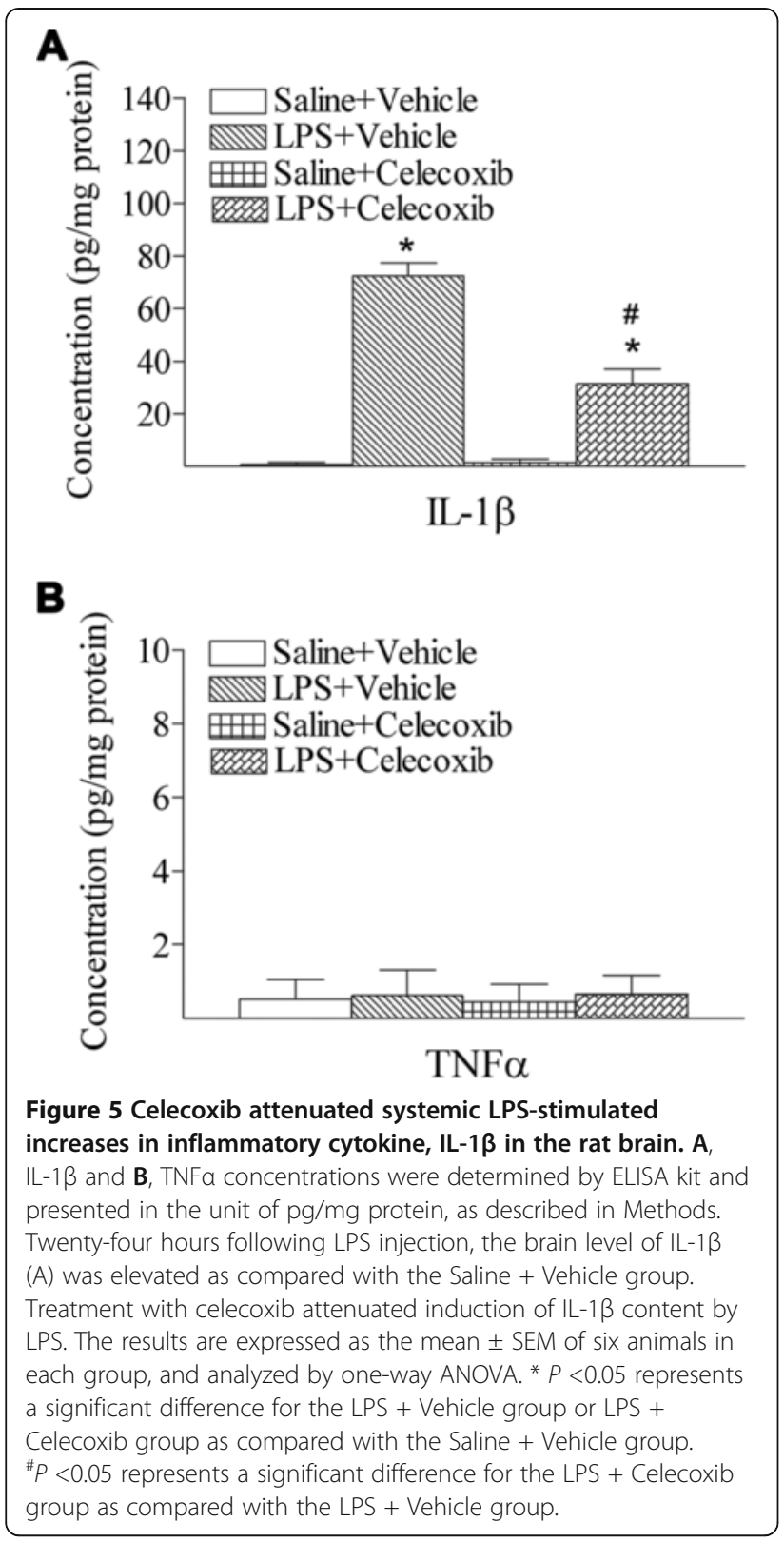

quantified by measuring the percent area containing GFAP immunostaining in the captured images. A higher percentage of GFAP immunostaining area was observed in the SN and striatum of neonatal LPS-exposed rat brains (Figure 6H). Celecoxib treatment reduced the number of activated astrocytes and the percentage of GFAP immunostaining area following LPS injection $(P<0.05$; Figure 6C, F-H).

Neonatal systemic LPS-induced inflammatory responses were also observed, as indicated by the increase in the percent area containing COX-2+ cells in the rat $\mathrm{SN}$ (Figure 7B, D, G, J) and striatum (Figure 7J) as compared to that in the control rat SN (Figure 7A, J) and striatum (Figure 7J), respectively. Double staining showed that most $\mathrm{COX}-2+$ cells in the $\mathrm{SN}$ were colocalized with GFAP + cells (Figure 7E, F), and some of these double-labeled cells were also co-localized with $\mathrm{TH}+$ neurons (Figure 7H, 7I). There were few COX-2+ cells that localized with Iba1-expressing microglia (data not shown). Treatment with celecoxib reduced the increase in percentage of COX-2 immunostaining area in the rat $\mathrm{SN}$ and striatum following LPS injection $(P<0.05$; Figure $7 \mathrm{C}, \mathrm{J})$.

\section{Discussion}

Our results indicated that, similar to i.c. LPS injection, systemic exposure to LPS through i.p. injection in neonatal rats cause brain inflammatory responses and sensorimotor behavioral impairment, as well as damage to the dopaminergic system in the rat brain $[3-6,29,34]$. Neonatal systemic LPS exposure resulted in brain inflammatory responses in the rat, as indicated by an increased number of activated microglia (Figure 4) and elevated IL-1 $\beta$ concentrations in LPS-treated rat brains (Figure 5A). Our previous data also show that activation of microglia plays a critical role in perinatal i.c. LPSinduced dopaminergic neuronal injury in rat brains $[4,5,8]$. Microglia, the major resident immune cells in the brain, have been identified as the major LPSresponsive cells in the CNS [10]. Microglia are detectable in the CNS of early embryos, but the largest population of newborn microglia emerges in late gestation and the early postnatal period in both humans and rats $[35,36]$. Thus, the LPS exposure in perinatal rat brains (P5, relevant to human intrauterine infection in late gestation) can produce substantial inflammatory responses in the brain. LPS treatment also induced the expression of COX-2 in cells that were double labeled with $\mathrm{TH}+$ (dopaminergic neurons) or GFAP + (astrocytes) cells in neonatal rat brains (Figure 7). Interactions between microglial cells and apoptotic neurons have been reported to selectively promote $\mathrm{COX}-2$ expression, and COX-2 may mediate microglial activation and may play a key role in amplifying the inflammatory response with toxic effects $[11,12]$. The current study showed that treatment with a selective COX-2 inhibitor, celecoxib, elicited anti-inflammatory effects, as evidenced by the attenuation of LPS-induced increases in the number of activated microglia and in the concentration of IL- $1 \beta$ in neonatal rat brains.

Increased expression of GFAP, an indicator of astrogliosis, was observed in the $\mathrm{SN}$ and striatum in rats $24 \mathrm{~h}$ after systemic LPS exposure (Figure 6). Treatment with celecoxib affected LPS-induced astrogliosis (Figure 6) and reduced the number of GFAP + and COX2+ double-labeled cells in LPS-exposed rat brains (Figure 7). Reactive astrocytes usually do not attack pathological targets, as do microglia, but instead wall off such targets to form a syncytium of inter- 


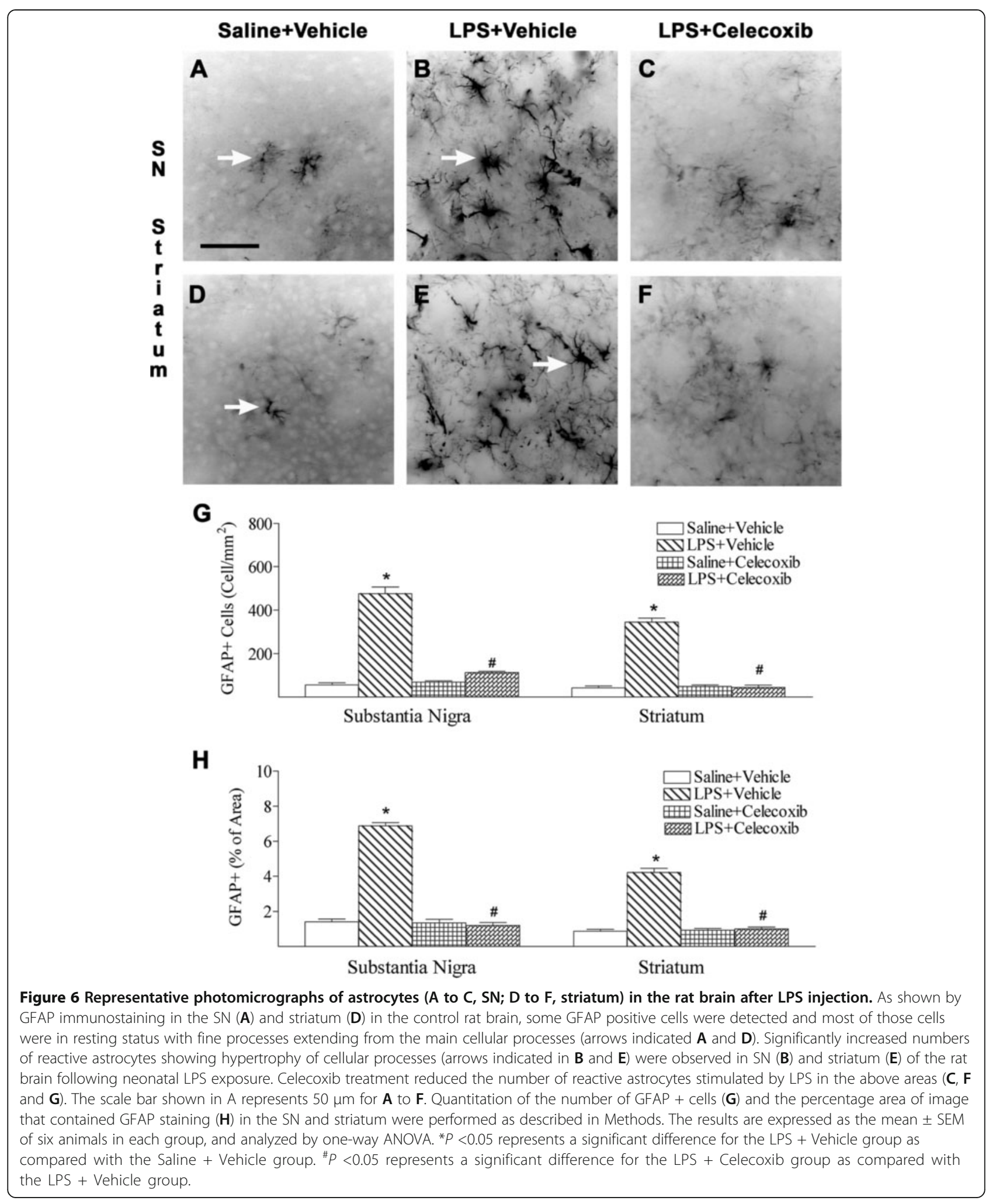




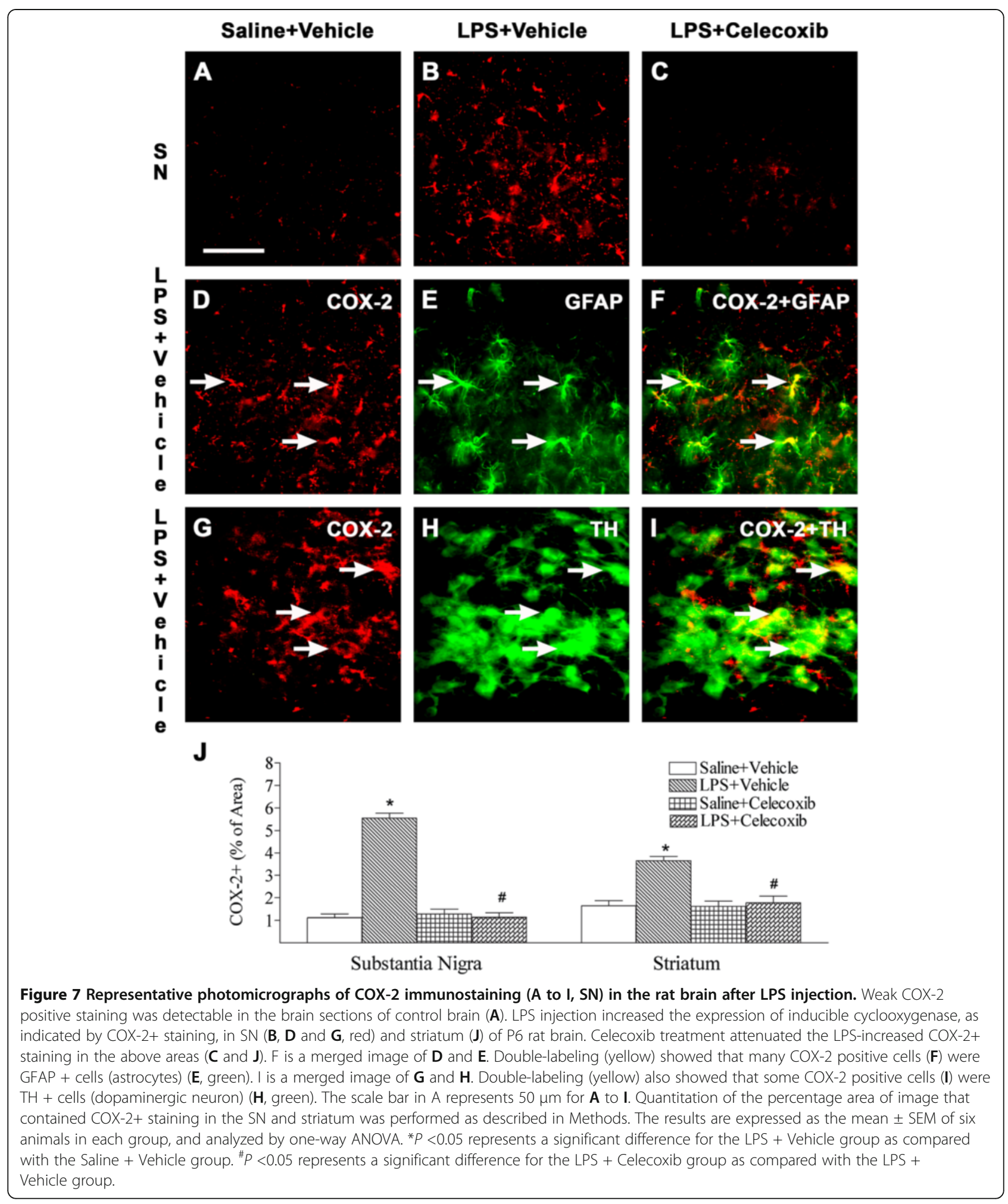

connected cells, both in healthy and diseased states [32,33]. Astrocytes produce both pro-inflammatory and antiinflammatory responses; for example, astrocytes may stimulate the microglia and secrete protective factors to the peripheral region at the same time [32]. $\alpha$-Synuclein has been shown to activate both microglia and astrocytes, and these interactions may contribute to dopamine quinine formation [37]. However, the precise mechanisms of interaction between astrogliosis and dopaminergic neuronal injury are unclear, and further studies are needed. 
Neonatal systemic LPS exposure resulted in dopaminergic system disturbances, as indicated by sensorimotor impairments, a decrease in the number of $\mathrm{TH}+$ cells in $\mathrm{SN}$, and increases in the expression of $\alpha$-synuclein and DAT proteins, and an increase in $\left[{ }^{3} \mathrm{H}\right] \mathrm{DA}$ uptake in rat brains (Figures 1, 2, 3). Neuroinflammation and $\alpha$-synuclein dysfunction have been proposed to potentiate each other; this may drive chronic progression of neurodegeneration [38]. The present study also showed that LPS exposure induced COX-2 expression in dopaminergic neurons of the rat SN (Figure 7). Increased COX-2 expression in dopaminergic cells under stressful conditions can facilitate dopamine oxidation to quinone species, triggering oxidative stress, and COX-2 overexpression in dopaminergic cells may also play a role in $\alpha$-synuclein accumulation $[11,39]$. Other reports have implied that $\alpha$-synuclein may modulate DAT function, and disruption of this modulatory process may permit increased re-uptake of high levels of intracellular dopamine by DAT, causing profound neurotoxicity [40,41]. Moreover, $\alpha$-synuclein can associate with the inner mitochondrial membrane and mitochondrial $\alpha$-synuclein accumulation results in complex I impairment in dopaminergic neurons and increased free radical production [42]. The current study found that treatment with the COX-2 inhibitor celecoxib attenuated the LPS-induced decrease in mitochondria complex I activity, dopaminergic injury and dopaminergic dysfunction. Therefore, the neuroprotective effects of COX-2 inhibition may be related to the blockade of COX-2-mediated dopamine oxidation and the inhibition of amplification of the inflammatory response, causing toxic effects $[11,12]$.

LPS may provoke a dramatic systemic response, including up-regulation of inflammatory mediators and procoagulant factors in the systemic circulation, and LPS may also cause diarrhea, changes in plasma protein binding capacity, and modulation of hepatic and/or intestinal microsomal cytochrome P450 (CYP) isozymes, thereby affecting the renal excretion of drugs [43,44]. Therefore, the central neuroprotective effect of celecoxib may result from not only direct COX-2 inhibition in the brain, but also the effects of celecoxib on peripheral inflammatory responses. Other reports have indicated that intracerebral administration of LPS in rodents induces strong increases in COX-2 expression, mainly in astroglia and microglia, whereas COX-1 expression was predominantly observed in microglia and did not increase [45]. However, it has been suggested that, owing to its predominant localization in microglia, COX-1 may be the major player in neuroinflammation, whereas COX-2, which is localized in neurons, may have a major role in models in which the neurons are directly challenged [46]. Therefore, COX-1 preferential inhibitors also need to be further investigated in neurodegenerative diseases.
COX-2 has been suggested to be associated with various inflammatory parameters and is thought to be involved in neurodegenerative processes, such as multiple sclerosis, amyotrophic lateral sclerosis, Parkinson's disease, Creutzfeldt-Jakob disease and Alzheimer's disease $[11,13]$. Celecoxib is a selective COX-2 inhibitor and has been shown to be the safest COX-2 inhibitor in terms of cardiovascular safety data [14]. The neuroprotective action of celecoxib has been observed in LPS-induced nigrostriatal neurodegeneration [15] and 6-hydroxydopamine (6-OHDA)-induced progressive dopaminergic neuron degeneration in a rat model of Parkinson's disease [16]. Our present results also suggested that celecoxib may provide protection against systemic LPS exposureinduced dopaminergic neuronal dysfunction and sensorimotor behavioral disturbances; these protective effects are likely associated with its anti-inflammatory properties. However, the neuroprotective effects of celecoxib are still controversial since celecoxib has been reported to prevent LPS-induced cognitive impairments in mice [47], but also to worsen spatial memory retention in rats [48]. Epidemiologic evidence suggests that celecoxib may delay the onset of Alzheimer's dementia [49], but there is no benefit from celecoxib in symptomatic Alzheimer's disease [50]. Thus, the chronic use of celecoxib may be beneficial only in the very early stages of the Alzheimer's disease process [51]. Detailed mechanisms of celecoxib involvement in reducing systemic LPS exposure-induced dopaminergic neuronal dysfunction and in protection against LPSinduced sensorimotor behavioral disturbances need further investigation.

\section{Conclusion}

Brain inflammation induced through systemic LPS exposure is clinically relevant, and our current findings indicated that systemic LPS exposure (P5) through an i.p. injection induced central inflammation; these inflammatory responses included induction of COX-2 expression in $\mathrm{TH}$ neurons and astrocytes. Our results also suggested that application of the COX-2 inhibitor celecoxib after LPS injection can attenuate the inflammatory response and improve LPS-induced impairment, including dopaminergic neuronal dysfunction and sensorimotor behavioral disturbances. The current results provide valuable information for developing strategies in the prevention and therapeutic treatment of neurodegenerative diseases.

\section{Abbreviations}

6-OHDA: 6-hydroxydopamine; APP: $\beta$-amyloid precursor protein; CNS: Central nervous system; COX-2: Cyclooxygenase-2; CYP: cytochrome P450;

DA: Dopamine; DAT: Dopamine transporter; DAPI: 4',6-diamidino-2phenylindole; DMSO: Dimethyl sulfoxide; ELISA: Enzyme-linked immunosorbent assay; GFAP: Glial fibrillary acidic protein; Iba1: Ionized calcium binding adapter molecule 1 ; IL1- $\beta$ : Interleukin 1- $\beta$; i.c: Intracerebral; i.p: Intraperitoneal; LPS: Lipopolysaccharide; P5: Postnatal day 5; 
PMSF: phenylmethylsulfonyl fluoride; PVDF: polyvinylidene difluoride; SN: Substantia nigra; TBS: Tris-buffered saline; TH: Tyrosine hydroxylase; TNFa: Tumor necrosis factor alpha.

\section{Competing interests}

The authors declare that they have no competing financial or personal interests, and that none of the authors' institutions have contracts relating to this research through which it may stand to gain financially now or in the future.

\section{Authors' contributions}

AK established the protocols and carried out the experiments, and drafted the manuscript. LTT and YP performed the experiments and the statistical analysis. ST and SN participated in the data analysis and helped to draft the manuscript. AJB was involved in editing drafts of the manuscript. LWF and ZC designed the study, coordinated the experiments and co-wrote the manuscript. All authors read and approved the final manuscript.

\section{Acknowledgements}

This work was supported by an NIH grant NS 54278, Newborn Medicine Funds from the Department of Pediatrics, University of Mississippi Medical Center, Jackson, MS, USA.

\section{Author details}

${ }^{1}$ Department of Pediatrics, Division of Newborn Medicine, University of Mississippi Medical Center, Jackson, MS 39216, USA. ${ }^{2}$ School of Medicine, Fu Jen Catholic University, Xinzhuang Dist, New Taipei City 24205, Taiwan. ${ }^{3}$ Department of Pharmacology, Toxicology and Therapeutics, Division of Toxicology, School of Pharmacy, Showa University, Shingawa-ku, Tokyo 142-8555, Japan

Received: 26 November 2012 Accepted: 21 March 2013

Published: 5 April 2013

\section{References}

1. Burd I, Balakrishnan B, Kannan S: Models of fetal brain injury, intrauterine inflammation, and preterm birth. Am J Reprod Immunol 2012, 67:287-294.

2. Clancy B, Finlay BL, Darlington RB, Anand KJ: Extrapolating brain development from experimental species to humans. Neurotoxicology 2007, 28:931-937.

3. Cai Z, Pang Y, Lin S, Rhodes PG: Differential roles of tumor necrosis factoralpha and interleukin-1 beta in lipopolysaccharide-induced brain injury in the neonatal rat. Brain Res 2003, 975:37-47.

4. Fan LW, Chen RF, Mitchell HJ, Lin RC, Simpson KL, Rhodes PG, Cai Z: a-Phenyl-n-tert-butyl-nitrone attenuates lipopolysaccharide-induced brain injury and improves neurological reflexes and early sensorimotor behavioral performance in juvenile rats. J Neurosci Res 2008, 86:3536-3547

5. Fan LW, Michell HJ, Rhodes PG, Cai Z: Alpha-phenyl-n-tert-butyl-nitrone attenuates lipopolysaccharide-induced neuronal injury in the neonatal rat brain. Neuroscience 2008, 151:159-168.

6. Fan LW, Mirchell HJ, Tien LT, Zheng B, Pang Y, Rhodes PG, Cai Z: Alphaphenyl-n-tert-butyl-nitrone reduces lipopolysaccharide-induced white matter injury in the neonatal rat brain. Dev Neurol 2008, 68:365-378.

7. Fan LW, Tien LT, Lin RC, Simpson KL, Rhodes PG, Cai Z: Neonatal exposure to lipopolysaccharide enhances vulnerability of nigrostriatal dopaminergic neurons to rotenone neurotoxicity in later life. Neurobiol Dis 2011, 44:304-316.

8. Fan LW, Tien LT, Zheng B, Pang Y, Lin RC, Simpson KL, Ma T, Rhodes PG, Cai Z: Dopaminergic neuronal injury in the adult rat brain following neonatal exposure to lipopolysaccharide and the silent neurotoxicity. Brain Behav Immun 2011, 25:286-297.

9. Romero R, Kadar N, Hobbins JC, Duff GW: Infection and labor: the detection of endotoxin in amniotic fluid. Am J Obstet Gynecol 1987, 157:815-819.

10. Lehnardt S, Lachance $C$, Patrizi S, Lefebvre S, Follett $P$, Jensen FE, Rosenberg PA, Volpe JJ, Vartanian T: The Toll-like receptor TLP4 is necessary for lipopolysaccharide-induced oligodendrocyte injury in the CNS. J Neurosci 2002, 22:2478-2486.
11. Bartels $A L$, Leenders $K L$ : Cyclooxygenase and neuroinflammation in Parkinson's disease neurodegeneration. Curr Neuropharmacol 2010, 8:62-68.

12. De Simone R, Ajmone-Cat MA, Minghetti L: Atypical antiinflammatory activation of microglia induced by apoptotic neurons: possible role of phosphatidylserine-phosphatidylserine receptor interaction. Mol Neurobiol 2004, 29:197-212.

13. Minghetti L: Cyclooxygenase-2 (COX-2) in inflammatory and degenerative brain diseases. J Neuropathol Exp Neurol 2004, 63:901-910.

14. Jones SC: Relative thromboembolic risks associated with COX-2 inhibitors. Ann Pharmacother 2005, 39:1249-1259.

15. Hunter RL, Dragicevic N, Seifert K, Choi DY, Liu M, Kim HC, Cass WA, Sullivan PG, Bing G: Inflammation induces mitochondrial dysfunction and dopaminergic neurodegeneration in the nigrostriatal system. J Neurochem 2007, 100:1375-1386.

16. Sánchez-Pernaute R, Ferree A, Cooper O, Yu M, Brownell AL, Isacson O: Selective COX-2 inhibition prevents progressive dopamine neuron degeneration in a rat model of Parkinson's disease. J Neuroinflammation 2004, 1:6.

17. Cunha NV, de Abreu SB, Panis C, Grassiolli S, Guarnier FA, Cecchini R, Mazzuco TL, Pinge-Filho P, Martins-Pinge MC: Cox-2 inhibition attenuates cardiovascular and inflammatory aspects in monosodium glutamateinduced obese rats. Life Sci 2010, 87:375-381.

18. Sato H, Bolli R, Rokosh GD, Bi Q, Dai S, Shirk G, Tang XL: The cardioprotection of the late phase of ischemic preconditioning is enhanced by postconditioning via a COX-2-mediated mechanism in conscious rats. Am J Physiol Heart Circ Physiol 2007, 293:H2557-H2564.

19. Altman J, Sudarshan K: Postnatal development of locomotion in the laboratory rat. Anim Behav 1975, 23:896-920.

20. Hermans RH, Hunter DE, McGivern RF, Cain CD, Longo LD: Behavioral sequelae in young rats of acute intermittent antenatal hypoxia. Neurotoxicol Teratol 1992, 14:19-129.

21. Altman J, Sudarshan K, Das GD, McCormick N, Barnes D: The influence of nutrition on neural and behavioral development. 3. Development of some motor, particularly locomotor patterns during infancy. Dev Psychobiol 1971, 4:97-114.

22. Deguchi K, Oguchi K, Matsuura N, Armstrong DD, Takashima S: Periventricular leukomalacia: relation to gestational age and axonal injury. Pediatr Neurol 1999, 20:370-374.

23. Meng SZ, Arai Y, Deguchi K, Takashima S: Early detection of axonal and neuronal lesions in prenatal-onset periventricular leukomalacia. Brain Dev 1997, 19:480-484.

24. Hadlock GC, Baucum AJ 2nd, King JL, Horner KA, Cook GA, Gibb JW, Wilkins DG, Hanson GR, Fleckenstein AE: Mechanisms underlying methamphetamine-induced dopamine transporter complex formation. J Pharmacol Exp Ther 2009, 329:169-174.

25. Nickell JR, Krishnamurthy S, Norrholm S, Deaciuc G, Siripurapu KB, Zheng G, Crooks PA, Dwoskin LP: Lobelane inhibits methamphetamine-evoked dopamine release via inhibition of the vesicular monoamine transporter-2. J Pharmacol Exp Ther 2010, 332:612-621.

26. Champy P, Höglinger GU, Féger J, Gleye C, Hocquemiller R, Laurens A, Guérineau V, Laprévote O, Medja F, Lombès A, Michel PP, Lannuzel A, Hirsch EC, Ruberg M: Annonacin, a lipophilic inhibitor of mitochondrial complex I, induces nigral and striatal neurodegeneration in rats: possible relevance for atypical parkinsonism in Guadeloupe. J Neurochem 2004, 88:63-69.

27. Hoglinger GU, Lannuzel A, Khondiker ME, Michel PP, Duyckaerts C, Feger J, Champy P, Prigent A, Medja F, Lombes A, Oertel WH, Ruberg M, Hirsch EC: The mitochondrial complex I inhibitor rotenone triggers a cerebral tauopathy. J Neurochem 2005, 95:930-939.

28. Chen YR, Chen CL, Zhang L, Green-Church KB, Zweier JL: Superoxide generation from mitochondrial NADH dehydrogenase induces selfinactivation with specific protein radical formation. J Biol Chem 2005, 280:37339-37348.

29. Fan LW, Pang Y, Lin S, Rhodes PG, Cai Z: Minocycline attenuates lipopolysaccharide-induced white matter injury in the neonatal rat brain. Neuroscience 2005, 133:1359-1368.

30. Pang Y, Cai Z, Rhodes PG: Disturbance of oligodendrocyte development, hypomyelination and white matter injury in the neonatal rat brain after intracerebral injection of lipopolysaccharide. Brain Res Dev Brain Res 2003, 140:205-214. 
31. Fan LW, Mirchell HJ, Tien LT, Rhodes PG, Cai Z: Interleukin-1ß-induced brain injury in the neonatal rat can be ameliorated by a-phenyl- $n$-tertbutyl-nitrone. Exp Neurol 2009, 220:143-153.

32. McGeer PL, McGeer EG: Glial reactions in Parkinson's disease. Mov Disord 2008, 23:474-483.

33. Pekny M, Nilsson M: Astrocyte activation and reactive gliosis. Glia 2005, 50:427-434.

34. Fan LW, Pang Y, Lin S, Tien LT, Ma T, Rhodes PG, Cai Z: Minocycline reduces lipopolysaccharide-induced neurological dysfunction and brain injury in the neonatal rat. J Neurosci Res 2005, 82:71-82.

35. Pont-Lezica L, Bechade C, Belarif-Cantaut Y, Pascual O, Bessis A: Physiological roles of microglia during development. J Neurochem 2011, 119:901-908.

36. Harry GJ, Kraft AD: Microglia in the developing brain: a potential target with lifetime effects. Neurotoxicology 2012, 33:191-206.

37. Klegeris A, McGeer EG, McGeer PL: Therapeutic approaches to inflammation in neurodegenerative disease. Curr Opin Neurol 2007, 20:351-357.

38. Gao HM, Zhang F, Zhou H, Kam W, Wilson B, Hong JS: Neuroinflammation and a-synuclein dysfunction potentiate each other, driving chronic progression of neurodegeneration in a mouse model of Parkinson's disease. Environ Health Perspect 2011, 119:807-814.

39. Chae SW, Kang BY, Hwang O, Choi HJ: Cyclooxygenase-2 is involved in oxidative damage and alpha-synuclein accumulation in dopaminergic cells. Neurosci Lett 2008, 436:205-209.

40. Sidhu A, Wersinger C, Vernier P: alpha-Synuclein regulation of the dopaminergic transporter: a possible role in the pathogenesis of Parkinson's disease. FEBS Lett 2004, 565:1-5.

41. Sidhu A, Wersinger $C$, Vernier P: Does alpha-synuclein modulate dopaminergic synaptic content and tone at the synapse? FASEB J 2004, 18:637-647.

42. Chinta SJ, Mallajosyula JK, Rane A, Andersen JK: Mitochondrial a-synuclein accumulation impairs complex I function in dopaminergic neurons and results in increased mitophagy in vivo. Neurosci Lett 2010, 486:235-239.

43. Opal SM: Endotoxins and other sepsis triggers. Contrib Nephrol 2010, 167:14-24.

44. Yang KH, Lee MG: Effects of endotoxin derived from Escherichia coli lipopolysaccharide on the pharmacokinetics of drugs. Arch Pharm Res 2008, 31:1073-1086.

45. Font-Nieves M, Sans-Fons MG, Gorina R, Bonfill-Teixidor E, Salas-Pérdomo A, Márquez-Kisinousky L, Santalucia T, Planas AM: Induction of COX-2 enzyme and down-regulation of COX-1 expression by lipopolysaccharide (LPS) control prostaglandin E2 production in astrocytes. J Biol Chem 2012, 287:6454-6568.

46. Choi SH, Aid S, Bosetti F: The distinct roles of cyclooxygenase- 1 and -2 in neuroinflammation: implications for translational research. Trends Pharmacol Sci 2009, 30:174-181.

47. El Sayed NS, Kassem LA, Heikal OA: Promising therapy for Alzheimer's disease targeting angiotensinconverting enzyme and the cyclooxygense-2 isoform. Drug Discov Ther 2009, 3:307-315.

48. Sharifzadeh M, Tavasoli M, Naghdi N, Ghanbari A, Amini M, Roghani A: Posttraining intrahippocampal infusion of nicotine prevents spatial memory retention deficits induced by the cyclo-oxygenase-2-specific inhibitor celecoxib in rats. J Neurochem 2005, 95:1078-1090.

49. Small GW, Siddarth P, Silverman DHS, Ercoli LM, Miller KJ, Lavretsky H, Bookheimer SY, Huang SC, Barrio JR, Phelps ME: Cognitive and cerebral metabolic effects of celecoxib versus placebo in people with age-related memory loss: randomized controlled study. Am J Geriatr Psychiatry 2008, 16:999-1009.

50. Breitner JC, Baker LD, Montine TJ, Meinert CL, Lyketsos CG, Ashe KH, Brandt J, Craft S, Evans DE, Green RC, Ismail MS, Martin BK, Mullan MJ, Sabbagh M, Tariot PN, ADAPT Research Group: Extended results of the Alzheimer's disease anti-inflammatory prevention trial. Alzheimers Dement 2011, 7:402-411.

51. Imbimbo BP, Solfrizzi V, Panza F: Are NSAIDs useful to treat Alzheimer's disease or mild cognitive impairment? Front Aging Neurosci 2010, 2:19.

doi:10.1186/1742-2094-10-45

Cite this article as: Kaizaki et al:: Celecoxib reduces brain dopaminergic neuronaldysfunction, and improves sensorimotor behavioral performance in neonatal rats exposed to systemic lipopolysaccharide. Journal of Neuroinflammation 2013 10:45.

\section{Submit your next manuscript to BioMed Central and take full advantage of:}

- Convenient online submission

- Thorough peer review

- No space constraints or color figure charges

- Immediate publication on acceptance

- Inclusion in PubMed, CAS, Scopus and Google Scholar

- Research which is freely available for redistribution 